\title{
A particular bigeminy during atrial tachycardia
}

\author{
C. Buttà • A. Tuttolomondo • L. Giarrusso • A. Pinto
}

Published online: 10 July 2014

(C) The Author(s) 2014. This article is published with open access at Springerlink.com

A 77-year-old female patient presented to the hospital's emergency department with palpitations. The electrocardiogram shows a supraventricular bigeminy where the premature beats are due to aberrant conduction (wider and deeper $\mathrm{S}$ waves from lead V1 to V5 and 'RSR' morphology in lead V6) but the rhythm is not sinus (Fig. 1). What is the mechanism?

Answer

You will find the answer elsewhere in this issue.

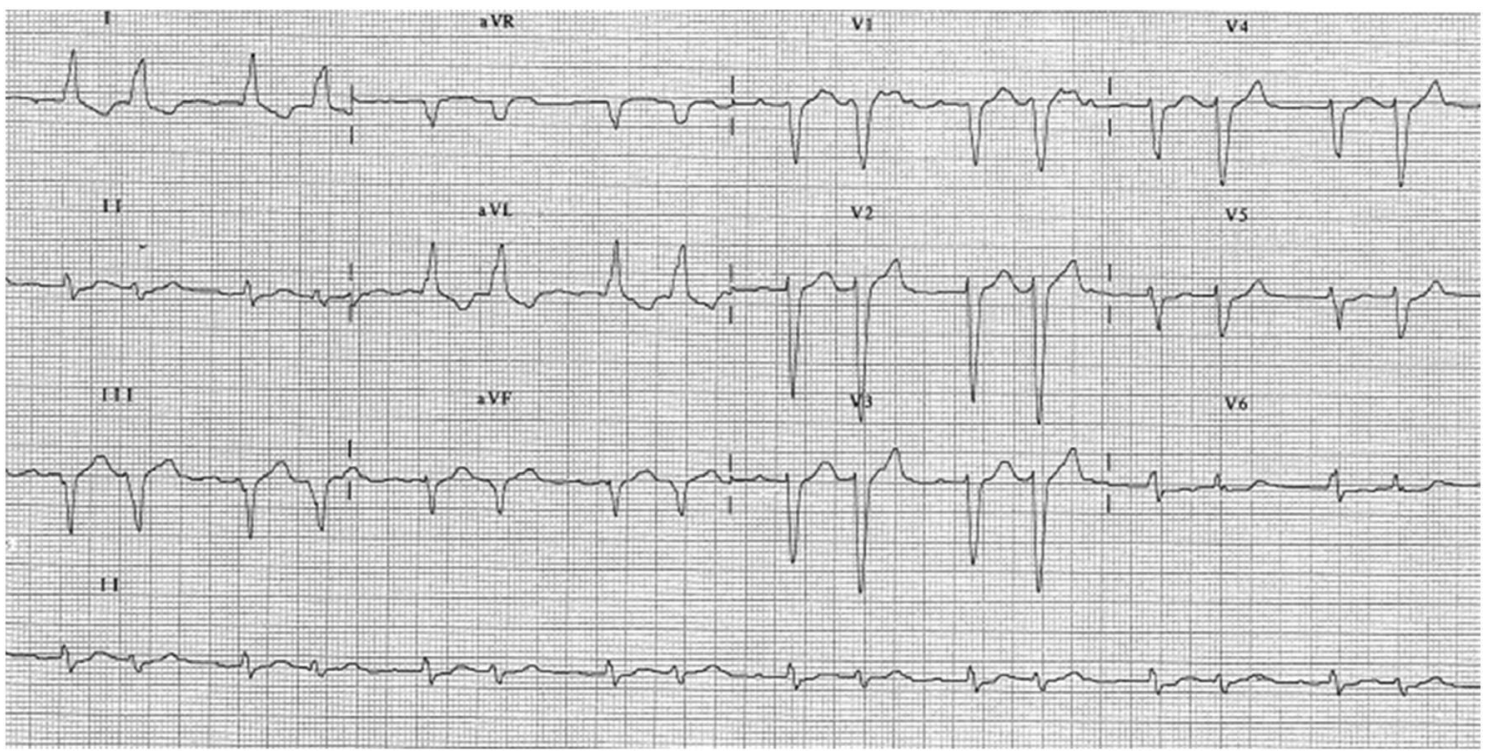

Fig. 1 A particular bigeminy with aberrant conduction during atrial tachycardia

C. Buttà $\cdot$ A. Tuttolomondo $\cdot$ L. Giarrusso $\cdot$ A. Pinto

U.O.C. Medicina Interna e Cardioangiologia, Dipartimento

Biomedico di Medicina Interna e Specialistica, Università degli Studi

di Palermo, Palermo, Italy

C. Buttà $(\bowtie)$

U.O.C. Medicina Interna e Cardioangiologia Dipartimento

Biomedico di Medicina Interna e Specialistica, Università degli Studi

di Palermo, Piazza delle Cliniche n ${ }^{\circ}$ 2, 90127 Palermo, Italy

e-mail: carmelob147@tiscali.it
Open Access This article is distributed under the terms of the Creative Commons Attribution License which permits any use, distribution, and reproduction in any medium, provided the original author(s) and the source are credited. 